\title{
Is it appropriate to perform anterior segment reconstruction in amblyopic eye following penetrating trauma in childhood?
}

\author{
Piotr Skopiński ${ }^{1,2}$, Kamil Szulborski ${ }^{1}$, Ewa Struzik ${ }^{1}$, Anna M. Ambroziak ${ }^{1}$, Ewa Langwińska-Wośko ${ }^{1}$ \\ ${ }^{1}$ Department of Ophthalmology, Medical University of Warsaw, Warsaw, Poland \\ ${ }^{2}$ Department of Histology and Embryology, Biostructure Center, Medical University of Warsaw, Warsaw, Poland
}

Videosurgery Miniinv 2015; 10 (4): 589-592

DOI: $10.5114 /$ wiitm.2015.55690

\begin{abstract}
We present a case of diagnostic and surgical management in an amblyopic eye following penetrating trauma in childhood. The 75-year-old female patient experienced the trauma at the age of 4. The eye was amblyopic, but after thorough investigations (ultrasonography, ultrabiomicroscopy, visual evoked potentials) the eye underwent anterior segment reconstruction. Visual evoked potentials allowed us to assess optic nerve function, while ultrabiomicroscopy allowed us to plan the surgical procedure. Although we observed quite a small visual acuity improvement, the subjective improvement reported by the patient was fairly significant (NEI VFQ-25 questionnaire). The cosmetic effect of the black pupil was also important.
\end{abstract}

Key words: penetrating eye trauma, amblyopic eye, anterior segment surgery, ultrabiomicroscopy, visual evoked potentials.

\section{Introduction}

Post-traumatic cataract surgery may represent a real challenge for surgeons due to potential intraoperative complications and abnormal anatomical structures [1]. It is especially difficult in cases with a history of eye trauma that occurred many years earlier. Performing surgical procedures in such cases may be controversial, as the risk of the operation may outweigh the potential benefits. In patients who have undergone penetrating eye trauma in childhood we can expect amblyopia ex anopsia [2].

The aim of the study is to present the case report of a diagnostic procedure and surgical management of a 75-year-old female patient who sustained penetrating trauma to her right eye at the age of 4. Following the trauma, the lens was almost completely resorbed and the remaining capsular bag became completely opaque. The patient underwent anteri- or segment reconstruction with an intraocular lens placed in the sulcus.

\section{Case report}

A 75-year-old female patient attended the ward to consult our doctors regarding the possibility of surgery on her right eye following penetrating trauma at the age of 4 years. The patient reported that the eye had been wounded by a fountain pen. As this occurred during World War II, the eye was only treated with conservative methods for about 2 months. The patient reported that vision in the affected eye was as good as in the healthy eye prior to the injury.

In the affected eye, the best-corrected visual acuity was counting fingers. In the left eye, the best-corrected visual acuity was 0.4 , as a result of the cataract. The eyes did not squint. The slit lamp examination re-

\section{Address for correspondence}

Kamil Szulborski MD, Department of Ophthalmology, Medical University of Warsaw, 13 Sierakowskiego St, 03-709 Warsaw, Poland,

phone: +48 880802 131, e-mail: donbors@yahoo.com 


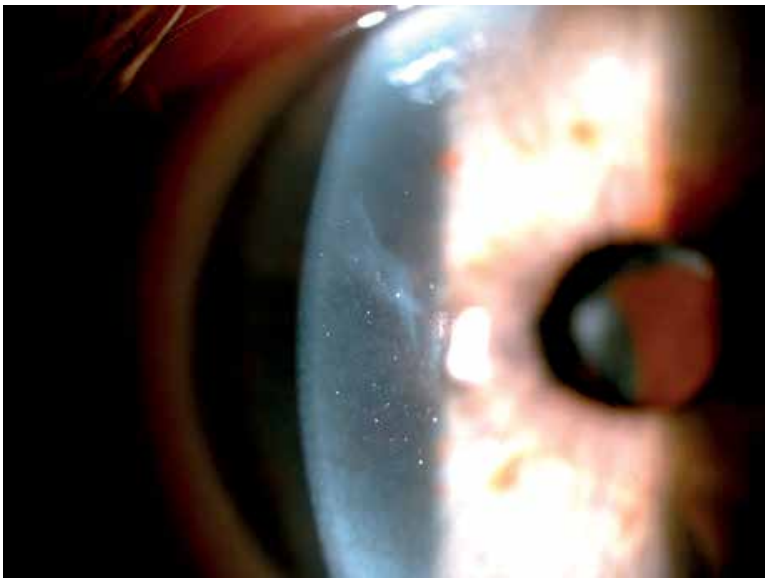

Photo 1. Slit-lamp photography showing the corneal scar after penetrating eye trauma

vealed a paracentral corneal scar, synechiae between the anterior capsule and iris, as well as leukocoria caused by an opaque capsular bag (Photos 1, 2).

The patient underwent accessory investigations, i.e. ultrasonography (USG), ultrabiomicroscopy (UBM) and flash visual evoked potentials (FVEPs). The USG was normal, and the UBM showed an intact anterior and posterior capsule, with intact ligaments, peripheral remnants of the lens and posterior synechiae of the iris and capsule (Photos $3 \mathrm{~A}, \mathrm{~B}$ ). The flash visual evoked responses (FVER), performed in accordance with International Society for Clinical Electrophysiology of Vision (ISCEV) standards [3], showed normal wave latencies in both eyes (Photo 4).

The patient underwent anterior segment reconstruction with an intraocular lens placed in the

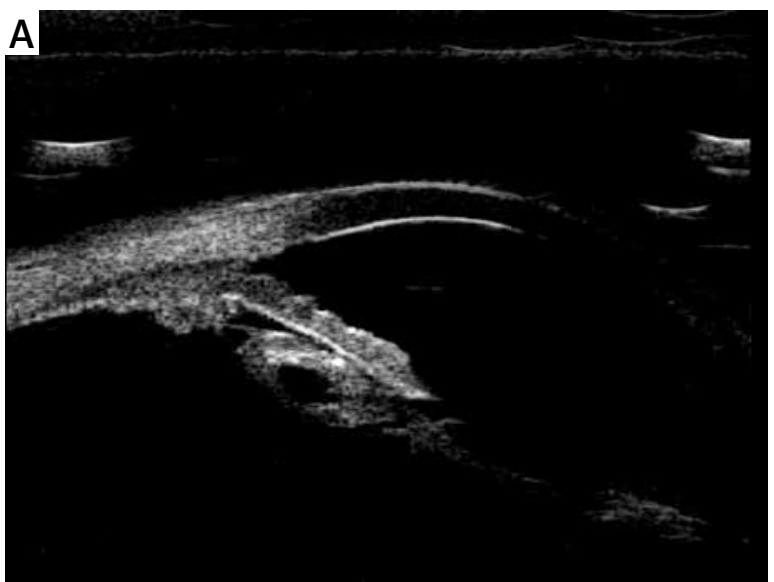

Photo 3 A, B. UBM examination showing an intact anterior and posterior capsule, with peripheral remnants of the lens
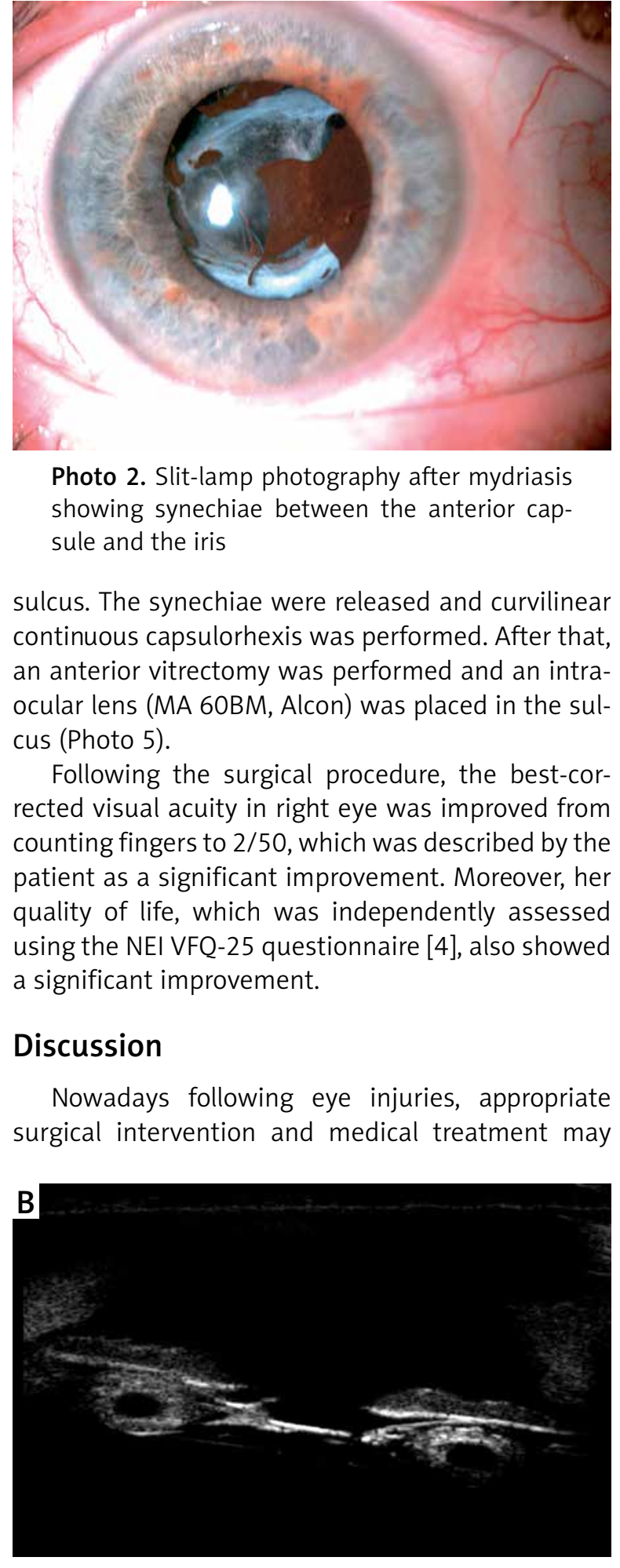

Photo 2. Slit-lamp photography after mydriasis showing synechiae between the anterior capsule and the iris

sulcus. The synechiae were released and curvilinear continuous capsulorhexis was performed. After that, an anterior vitrectomy was performed and an intraocular lens (MA 60BM, Alcon) was placed in the sulcus (Photo 5).

Following the surgical procedure, the best-corrected visual acuity in right eye was improved from counting fingers to $2 / 50$, which was described by the patient as a significant improvement. Moreover, her quality of life, which was independently assessed using the NEI VFQ-25 questionnaire [4], also showed a significant improvement.

\section{Discussion}

Nowadays following eye injuries, appropriate surgical intervention and medical treatment may 


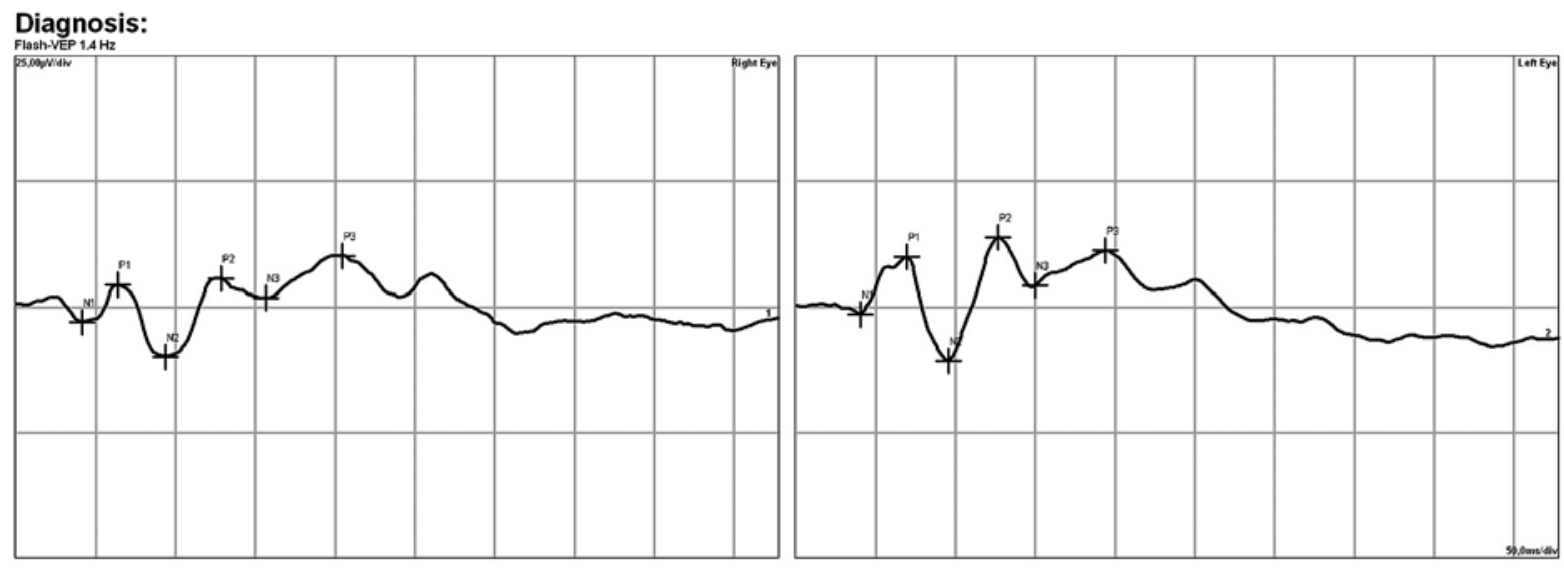

Photo 4. Flash visual evoked potentials in the right and left eye

enable the recovery of functional levels of visual acuity in the majority of adult patients $[5,6]$. On the other hand, severe eye injuries in children may lead to amblyopia as the process of vision and perception development takes up to 10 years [7].

Performing surgical procedures in amblyopic eyes may seem to be controversial. There are only a few publications that have specifically addressed amblyopia and cataract surgery [8-10]. As reported by Hale et al., the decision to operate on the amblyopic eye depends on a clear understanding of the possible symptoms, functional impairments and surgical outcomes [8]. Williams et al. suggested that a nationwide survey was needed to establish formal guidance in the context of cataract planning in amblyopia [9].

Our patient experienced penetrating eye trauma at the age of 4 , with consequent medical treatment only. The lens was almost resorbed with posterior synechiae, so the patient required anterior segment reconstruction surgery. In such an eye we could expect deprivational amblyopia [2], but the patient was qualified for anterior segment surgery due to a normally functioning optic nerve and lack of squint. Although the visual acuity could not be predicted prior to the surgery, and the empirical improvement following it was quite small, the subjective improvement, as described by the patient, was significant, confirmed using the NEI VFQ-25 questionnaire. Moreover, the procedure enabled an eye fundus slit lamp examination and the cosmetic effect of a black pupil was also achieved. Furthermore, as monocular patients are more affected by trauma of their better eye, the improvement from counting fingers to $2 / 50$ in the affected one may seem to be important.

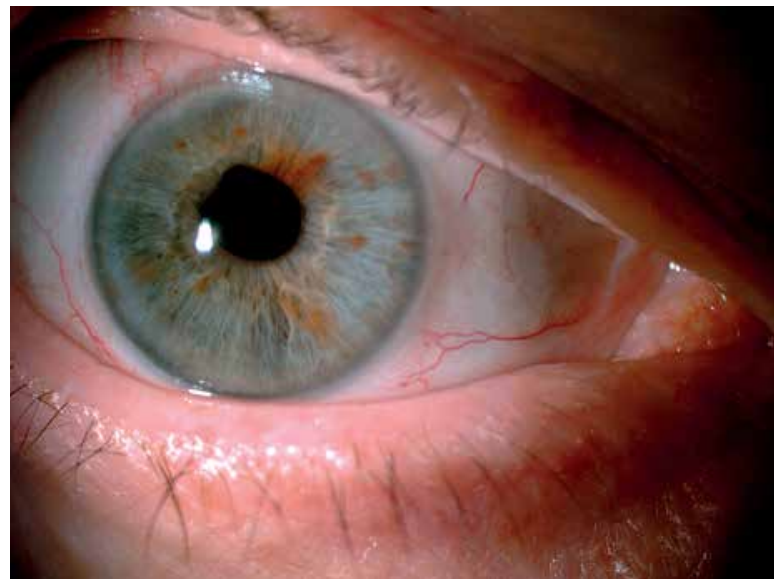

Photo 5. Slit-lamp photography showing the eye at the final visit following anterior segment reconstruction

The accessory investigations, including USG, UBM and FVEPs, allowed us to qualify the patient for surgery and to provide full information regarding her state of vision. It should be emphasized that electrophysiological testing allowed us to assess the function of the optic nerve, while UBM aided the planning of the surgical procedure, which was performed 71 years after the penetrating eye trauma.

\section{Conflict of interest}

The authors declare no conflict of interest.

\section{References}

1. MacEwen CJ. Eye injuries: a prospective survey of 5671 cases. Br J Ophthalmol 1989; 73: 888-94.

2. MacEwen CJ, Baines PS, Desai P. Eye injuries in children: the current picture. Br J Ophthalmol 1999; 83: 933-6. 
3. Odom JV, Bach M, Brigell M, et al. ISCEV standard for clinical visual evoked potentials (2009 update). Doc Ophthalmol 2010; 120: 111-9.

4. Mangione CM, Lee PP, Pitts J, et al. Psychometric properties of the National Eye Institute Visual Function Questionnaire (NEIVFQ). NEI-VFQ Field Test Investigators. Arch Ophthalmol 1998; 116: 1496-504.

5. May DR, Kuhn FP, Morris RE, et al. The epidemiology of serious eye injuries from the United States Eye Injury Registry. Graefes Arch Clin Exp Ophthalmol 2000; 238: 153-7.

6. Kuhn F, Morris R, Witherspoon CD, et al. A standardised classification of ocular trauma terminology. Graefes Arch Clin Exp Ophthalmol 1996; 234: 399-403.

7. Abbott J, Shah P. The epidemiology and etiology of pediatric ocular trauma. Surv Ophthalmol 2013; 58: 476-85.

8. Hale JE, Murjaneh S, Frost NA, Harrad RA. How should we manage an amblyopic patient with cataract? Br J Ophthalmol 2006; 90: 132-3.

9. Williams GS, Radwan M, Menon J. Cataract surgery planning in amblyopic patients - which eye first? Ulster Med J 2013; 82: 82-4.

10. Skopiński P, Woronkowicz M, Langwińska-Wośko E, et al. Multi-procedure management in an eyeglasses-related open globe injury. Videosurgery Miniinv 2014; 9: 101-6.

Received: 2.10.2015, accepted: 23.10.2015. 